\title{
COMMENT \\ ON "A POSITIVE THEORY OF \\ LEGISLATIVE INTENT"
}

\author{
MiChAEL MUNGER* \\ I \\ INTRODUCTION
}

\begin{abstract}
It is emphatically the province and duty of the judicial department to say what the law is .... If two laws conflict with each other, the courts must decide on the operation of each .... This is the very essence of judicial duty. ${ }^{1}$
\end{abstract}

The law is a sort of hocus-pocus science. ${ }^{2}$

Upon initial consideration, these two perspectives on the practice of judicial interpretation seem to conflict. The recent literature on signaling games and the canons of interpretation has shown that the duty of courts "to say what the law is" and "hocus-pocus" are in fact quite consistent. The reason, of course, is that judges operate in a context of significant uncertainty. They are uncertain about two things: what the legislature said when it passed the law (what does the language mean, if it means anything?) and what the legislature would say now (are the coalitions or institutions responsible for motivating decisions different?). This commentary addresses the strengths and weaknesses of the model utilized and the conclusions reached by Schwartz, Spiller, and Urbiztondo in their article. $^{3}$

II

\section{The Problem With Signaling Games}

To analyze judicial interpretation, the article uses a method called the signaling game, which combines recent advances in information theory with the notion of sequential equilibrium. This technique has become common in professional journals, and several other authors, including Spiller himself, have

\footnotetext{
Copyright $\mathbb{O} 1994$ by Law and Contemporary Problems

* Pearsall Professor of State and Local Government, Department of Political Science University of North Carolina-Chapel Hill.

1. Marbury v. Madison, 5 U.S. (1 Cranch) 137, $177-78$ (1803) (Marshall, C.J.).

2. Charles Macklin, Love $A$ la MODE act 2 , sc. 1 (1759).

3. Edward P. Schwartz et al., A Positive Theory of Legislative Intent, 57 LAW \& CONTEMP. ProBS. 51 (Winter 1994).
} 
used it before to model judicial decisionmaking. ${ }^{4}$ The now-standard results, known to most people who have followed the literature, are that "types" of agents can be distinguished, or separated, by principals under two general classes of circumstances. The "types" that may be important may have to do with whether the agent is competent or incompetent, lazy or energetic, or (as in the case of concern in the principle article), intensely interested or apathetic. The two sets of conditions for useful equilibria are as follows.

First, it must be possible for explicit costs for misrepresenting type, known to the agent ex ante, to be written into the contract or other formal relation between actors. Second, the principal must be able credibly to threaten the agent with the implicit ex post costs of misrepresenting type. The first approach is difficult (that is, costly) because it requires close monitoring, exact definition of task, and little scope for initiative by the agent. The second approach is difficult because many threats to impose cost ex post are incredible. The principal knows, and the agent knows the principal knows, that imposing costs on the agent also imposes costs on the principal. Consequently, in equilibrium, the threatened punishment is never meted out.

Unfortunately, this very interesting and important approach has become a bit hackneyed. It seems that the signaling game theory is now used in many circumstances because it is trendy and appears methodologically sophisticated, rather than because it adds anything other than jargon and tedium to the problem being analyzed. The "separating" and "pooling" equilibrium approach is lifted and applied to new problems like a template, forcing new problems to fit a particular, stylized set of assumptions. ${ }^{5}$

On first glance, the Schwartz, Spiller, and Urbiztondo article seems to be a good target for these criticisms. Consider the assumptions required before the authors can apply the signaling game/sequential equilibrium approach.

1. The principal, or at least the source of legislation with the power to enforce its will, is "the" Congress. "It" is a unitary actor, and it has fixed and well-defined transitive (in fact, linear!) preferences over outcomes.

2. The relevant policy space, for both Congress and the Supreme Court, is unidimensional.

3. The choice set for Congress is binary: write specific legislation or write vague legislation.

In addition, consider the first results generated by the approach. Well into the article, after six lemmas, one proposition, and innumerable definitions of

4. E.g., Pablo T. Spiller \& Matthew Spitzer, Judicial Choice of Legal Doctrine, 8 J. L. ECON. \& ORG. 8 (1992).

5. The criticisms offered here of the signaling game approach obviously do not apply to the new literature advancing the theory to relax the assumptions I have criticized. For an excellent review of important, and appropriate, applications of signaling theory in political science, see JEFFREY BANKS, Signaling Games in Political SCIENCE (1991). 
complex notation, the authors summarize the results of the article to that point: "If there is signaling, then the signaling Congress must either care substantially

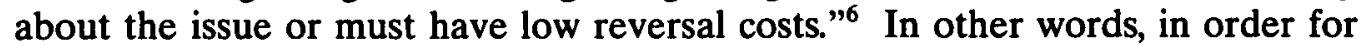
Congress to incur the costs of writing detailed legislation, it must either think the issue is important or believe it can reverse the Court without much cost; otherwise, all legislation would be vague. So far, all that the authors have proved is that it is possible to take a well-known theorem from one setting, insert words appropriate for the "new" problem being considered, and then show that the theorem still holds.

\section{III}

\section{The Power of Signaling Games}

However, labeling the principal article just another signaling game would be quite wrong. There is more to the article for the patient reader, and it is a significant advance in the literature. There are two separate results worthy of the attention of scholars interested in judicial interpretation.

The first is the treatment of uncertainty. While the model is not complex, it does account for uncertainty of both the Congress and the Supreme Court in far more sophisticated a fashion than in any previous work. There are two sources of uncertainty in the model: (1) Congress's uncertainty about its true reversal costs, and (2) the Supreme Court's uncertainty about the true intensity of preference of Congress. The first type of uncertainty allows the model to incorporate changes in Congress resulting from election and retirement, and forces an intertemporal perspective that is an accurate, yet elegant, representation of reality.

The second type of uncertainty captures the fundamental logic of the signaling game in a way that most models pass over: The reason the Court reads Congress's legislation carefully is not just to find the "plain meaning" of the statute. Rather, the Court also reads the statute to find out what Congress will do if the Court interprets the statute in a way Congress dislikes. This insight provides interesting and unexpected explanations for the focus of the courts on interpretation of statutes passed by legislatures. Most importantly, these insights could not have been developed without the sophisticated and appropriately abstract signaling model the authors have created.

The second major advance in the article is the substantive result in Proposition $2 .^{7}$ This finding, once stated, is intuitive, but it is hardly obvious. The result is that if the Court is certain about the preferences of Congress, there will be no signaling and all legislation will be vague. Further, if there is great uncertainty about the intensity of preference of Congress, no signaling will be observed. Only if uncertainty is moderate is it sequentially rational for Congress to write specific legislation. Nailing down these underlying conditions is exactly

6. Schwartz et al., supra note 3 , at 69.

7. Id. 
the sort of approach required for the development of a useful formal literature on the courts.

Again, this result suggests a variety of nonobvious questions with testable implications. For example, does Congress ever find it in its interest to affect the level of uncertainty of the Court? After all, if no signaling takes place, but reversal costs are low, Congress will spend all its time rewriting existing (but badly interpreted) statutes. What mechanisms has Congress evolved for solving this problem? Likewise, the Supreme Court would prefer not to have all its decisions reversed and the statutes rewritten; what mechanisms other than interpreting legislation has the Court come up with for reducing its uncertainty about reversal costs?

The real point, though it is beyond the scope of the Schwartz, Spiller, and Urbiztondo article, is that nonsignaling equilibria where uncertainty is high are not pareto optima. ${ }^{8}$ Even if the preferences of Congress and the Court diverge, they may find it in their cooperative interest in some circumstances to reduce the level of uncertainty the Court has about congressional preferences. This is an entirely unexplored area of research, and Schwartz, Spiller, and Urbiztondo should be congratulated for having pointed the way.

8. Pareto optima are outcomes upon which it is impossible to improve, without harming at least one participant in the game. In this case, outcomes where Congress has legislated vaguely and then must respond to judicial decisions that poorly interpret its statutes are not pareto optima. 